\title{
Assessment of the Mutations of p53 Suppressor Gene and Ha- and Ki-ras Oncogenes in Malignant Mesothelioma in Relation to Asbestos Exposure: A Study of 12 American Patients
}

\author{
Fumihiko KITAMURA ${ }^{1,4}$, Shunichi ARAKI ${ }^{1,4 *}$, Yasunosuke SUZUKI ${ }^{2}$, \\ Kazuhito YOKOYAMA ${ }^{1}$, Takeshi TANIGAWA ${ }^{1,5}$ and Ryu IWASAKI ${ }^{3}$ \\ ${ }^{1}$ Department of Public Health and Occupational Medicine, Graduate School of Medicine, The University of \\ Tokyo, 7-3-1, Hongo, Bunkyo-ku, Tokyo 113-0033, Japan \\ ${ }^{2}$ Deparment of Community Medicine, Mount Sinai School of Medicine, 1 Gestave L. Levy Place, New York, NY \\ 10029-6574, U.S.A. \\ ${ }^{3}$ Department of Gene Analysis, Mitsubishi Kagaku Bio-Clinical-Laboratories, Inc., 3-30-1, Shimura, Itabashi- \\ ku, Tokyo 174-0056, Japan \\ Present: \\ ${ }^{4}$ National Institute of Industrial Health, 6-21-1, Nagao, Tama-ku, Kawasaki 214-8585, Japan \\ ${ }^{5}$ Institute of Community Medicine, University of Tsukuba, 1-1-1, Tennodai, Tsukuba-City, Ibaragi 305-8575, \\ Japan
}

Received February 26, 2001 and accepted November 30, 2001

\begin{abstract}
In our previous study, we found no genetic alteration in exons 1 and 2 of Ha- and Ki-ras oncogenes nor in exons 5 to 9 of the p53 suppressor gene in seven Japanese malignant mesothelioma patients exposed to asbestos. To examine further whether malignant mesothelioma due to asbestos has genetic alterations in the p53 suppressor gene and in $\mathrm{Ha}$ - and $\mathrm{Ki}$-ras oncogenes, we analyzed point mutations of these genes in paraffin embedded operative open biopsied samples of the primary tumor of malignant mesothelioma in twelve American patients. The genetic analysis was conducted by the PCR-SSCP (polymerase chain reaction single-strand conformation polymorphism) method in all patients and by sequencing analysis of DNA bases in the two patients with suspected gene mutation. The analysis of the $\mathbf{p 3 3}$ suppressor gene showed an amino acid converting mutation of exon 7 in one patient and a polymorphism of exon 6 in another patient; the former patient was a heavy smoker with a biphasic cell type. No genetic alteration was found in exons 1 and 2 of Ha- and Ki-ras oncogenes in any of the patients. The results suggest that the effects of asbestos on the p53 suppressor gene and Ha- and Ki-ras oncogenes in malignant mesothelioma are negligible. Further studies are needed to examine whether the observed mutation of the p53 suppressor gene is due to the combined effects of asbestos and smoking or to other unknown factors.
\end{abstract}

Key words: Malignant mesothelioma, Asbestos, p53 suppressor gene, ras oncogene, PCR-SSCP analysis, Sequencing analysis, Primary tumor

*To whom correspondence should be addressed. 
Table 1. Twelve American operative open biopsied patients with malignant mesothelioma

\begin{tabular}{cccccc}
\hline No. & Sex & Age at biopsy (yrs) & Asbestos exposure & Cell types of mesothelioma & Brinkman's Index* \\
\hline 1 & Male & 56 & + & Epithelial & Unknown \\
2 & Male & 56 & + & Biphasic & 1050 \\
3 & Male & 57 & + & Epithelial & 800 \\
4 & Male & 57 & + & Epithelial & Unknown \\
5 & Male & 61 & + & Biphasic & Unknown \\
6 & Male & 63 & + & Epithelial & Unknown \\
7 & Male & 64 & + & Fibrous & Unknown \\
8 & Male & 67 & + & Fibrous & 320 \\
9 & Male & 68 & + & Epithelial & Unknown \\
10 & Female & 45 & Unknown & Epithelial & Unknown \\
11 & Female & 66 & + & Epithelial & Unknown \\
12 & Female & 66 & Unknown & Epithelial & Unknown \\
\hline
\end{tabular}

* Number of cigarettes per day multiplied by years of smoking.

\section{Introduction}

Malignant mesothelioma is caused by exposure to asbestos $^{1}$, which can damage DNA through the production of reactive oxygen ${ }^{2}$. Single point mutation of the p53 suppressor gene has been reported in 2 of 4 malignant mesothelioma cell lines ${ }^{3)}$ and in 2 of 20 cell lines ${ }^{4}$. In the former study, $\mathrm{CGC} \rightarrow \mathrm{C} \underline{\mathrm{AC}}$ transition in codon 175 (Exon 5) and G $\underline{G C} \rightarrow$ GAC transition in codon 245 (Exon 7) were demonstrated. In the latter, $\underline{\mathrm{GGC}} \rightarrow \underline{\mathrm{AGC}}$ transition in codon 245 (Exon 7) and $\underline{\mathrm{CCT}} \rightarrow \underline{\mathrm{TCT}}$ transition in codon 278 (Exon 8 ) were reported. No mutation of the Ki-ras oncogene has been observed in malignant mesothelioma cell lines ${ }^{4}$.

The mutation observed in the cell lines requires careful interpretation, as point mutation of genes can occur during serial passage in vitro ${ }^{5}$. Therefore, analysis of the genes of primary tumors is essential. Only one mutation in the p53 suppressor gene has been found in fifteen malignant mesothelioma patients, a $\underline{G G A} \rightarrow \underline{\text { TGA transversion in codon }}$ $266(\text { Exon } 8)^{6}$. Also, one silent mutation has been observed in the p53 suppressor gene of eleven primary malignant mesothelioma patients ${ }^{7}$. In other studies, no alteration in the Ha-ras oncogene was found in eleven primary tumors of malignant mesothelioma including those from cases with asbestos exposure ${ }^{8)}$, and no alteration in the $\mathrm{p} 53$ suppressor gene was demonstrated in thirteen primary tumors of malignant mesothelioma, of which only two cases had a history of asbestos exposure ${ }^{9}$. We also failed to find mutations of the p53 suppressor gene and Ha- and Ki-ras oncogenes in seven primary tumors from Japanese malignant mesothelioma patients exposed to asbestos ${ }^{10}$.

In the present study, we analyzed the p53 suppressor gene and Ha- and Ki-ras oncogenes in the primary tumors of twelve American malignant mesothelioma patients ten of whom had a definite history of asbestos exposure. Genetic analysis was conducted using the PCR-SSCP (polymerase chain reaction single-strand conformation polymorphism) method in all patients. Sequencing of DNA was carried out in two patients with suspected gene mutation and the factors causing the mutations are discussed.

\section{Materials and Methods}

One of the present authors (Y.S.), a qualified pathologist, collected all open biopsied specimens from twelve patients with malignant mesothelioma for pathologic examination, together with data on the sex, age, asbestos exposure, cell types of malignant mesothelioma, and smoking history of the patients (Table 1). The period of tissue fixation using neutral formalin was less than two days.

DNA was extracted from the formalin-fixed and paraffinembedded tissues of all the patients by the following standard method $^{11)}$ : From a block of the tissue specimens, 5-10 $\mu \mathrm{m}$ sections were dissected. An area precisely corresponding to that of the tumor lesion was excised from the section, deparaffinized, and then digested with Proteinase K (Boehringen Mannheim GmbH, Mannheim). DNA was purified by means of phenol-chloroform extraction and ethanol precipitation, and was amplified by 30 to 40 cycles of polymerase chain reaction (PCR $)^{12}$ through the use of a Gene Amplification PCR System 9600 (Perkin-Elmer Ceutus, Norwalk, California). In the PCR, codons 1 to 31 (exon 1) and 34 to 93 (exon 2) of the Ha-ras oncogene were amplified, as mutation frequently occurs at codons 12,13 and $61^{13)}$. 
Table 2. Results of p53, Ha-ras and Ki-ras gene analysis in 12 patients

\begin{tabular}{|c|c|c|c|c|c|c|c|c|c|}
\hline \multirow{2}{*}{ No. } & \multicolumn{5}{|c|}{ p53 } & \multicolumn{2}{|c|}{ Ha-ras } & \multicolumn{2}{|c|}{ Ki-ras } \\
\hline & Exon 5 & 6 & 7 & 8 & 9 & Exon 1 & 2 & Exon 1 & 2 \\
\hline 1 & -* & - & - & - & - & - & - & - & - \\
\hline 2 & $-*$ & -* & M & - & $-^{*}$ & -* $^{*}$ & $\mathrm{Nd}$ & $-^{*}$ & _* \\
\hline 3 & - & - & - & - & - & - & $\mathrm{Nd}$ & - & _* \\
\hline 4 & - & - & - & - & - & - & - & - & - \\
\hline 5 & - & $\mathrm{P}$ & - & - & - & - & - & - & - \\
\hline 6 & $-*$ & -* & -* & $-^{*}$ & ${ }^{*}$ & $-^{*}$ & -* $^{*}$ & $-^{*}$ & _* \\
\hline 7 & $-*$ & $-*$ & - & $-*$ & - & - & - & - & - \\
\hline 8 & - & - & - & - & - & - & - & - & - \\
\hline 9 & - & - & - & - & - & - & - & - & - \\
\hline 10 & - & - & - & - & - & - & - & - & - \\
\hline 11 & $-*$ & - & - & - & - & - & - & - & - \\
\hline 12 & $-*$ & $-*$ & $-*$ & $-*$ & $-*$ & - & $-*$ & - & - \\
\hline
\end{tabular}

-: Wild type, M: Mutation, P: Polymorphism, Nd: Not detected. * Electrophoresis was conducted by adding only $5 \%$ glycerol to gels.

Codons 1 to 37 (exon 1) and 48 to 80 (exon 2) of the Ki-ras oncogene were also amplified. Similarly, codons 126 to 307 (exons 5 to 9) of the p53 suppressor gene were amplified. The primers ${ }^{10)}$ of the PCR used in this study are shown in the Appendix. The PCR products were further amplified with $\left[\alpha-{ }^{32} \mathrm{P}\right] \mathrm{dCTP}$ by 20 to 40 cycles in the PCR System 9600 for PCR-SSCP analysis, and were then subjected to electrophoresis at 35 watts using $5 \%$ polyacrylamide gels containing glycerol at 5\% and $10 \%$; usage at two different concentrations of glycerol in the gels was expected to yield higher sensitivity in the latter study, i.e. this could decrease the possibility of false negative results ${ }^{14}{ }^{15}$. The electrophoresis time was 2 to 3 hours, depending on the length of the amplified nucleotide. The gel was dried and exposed to X-ray film at room temperature for 3 to 24 hours with an intensification screen.

DNA was also extracted from the leucocytes of a healthy male volunteer, 29 years of age, and it was used as a normal control. Similarly, a DNA sample which had a GGC to GTC transversion at codon 12 (Exon 1) in Ha-ras oncogene and an AGA to ACA transversion at codon 280 (Exon 8) in the p53 suppressor gene and was obtained from a cell line of bladder cancer was used as a positive control. These DNA samples were analyzed by the same method as the samples taken from the mesothelioma patients.

Sequencing analyses of the Ha- and Ki-ras oncogenes and the p53 suppressor gene for the codons described above were conducted in two patients in whom mutations were suspected by the SSCP analysis (Patients 2 and 5, Table 1) on the DNA samples acquired from abnormal bands on gels. Sequencing reactions were carried out with Dye Deoxy
Terminator Cycle Sequencing kit and the products were analyzed using a 373A Sequencer (Applied Biosystems Inc., Foster City, California).

\section{Results}

\section{PCR-SSCP analysis}

Table 2 summarizes the results of PCR-SSCP and sequencing analysis of the 12 patients. Mobility shift from the normal band of the $\mathrm{p} 53$ suppressor gene was detected in exon 6 of Patient 5 and in exon 7 of Patient 2 (Fig. 1). Patient 2 was a heavy smoker (Table 1). No mobility shift of Haand Ki-ras oncogenes was found in any of the 12 patients by SSCP analysis.

\section{Sequencing analysis}

The results of the sequencing analysis of the p53 suppressor gene in Patients 2 and 5 are shown in Figure 2. Base changes in codon 213 in exon 6 (CGA $\rightarrow$ CGG, No amino acid converted) and codon 233 in exon 7 (CAC $\rightarrow$ CGC, Histidine $\rightarrow$ Arginine) were found in Patients 5 and 2, respectively.

\section{Discussion}

Following our previous study ${ }^{10)}$, we analyzed directly primary tumors of malignant mesothelioma to examine changes in the p53 suppressor gene and Ha- and Ki-ras oncogenes in ten American patients with a definite history of asbestos exposure and also in two American patients with an unknown history of asbestos exposure. The transition of $\mathrm{CAC} \rightarrow \mathrm{CGC}$ was found in codon 233 (Exon 7) of the p53 


\section{Exon 6}

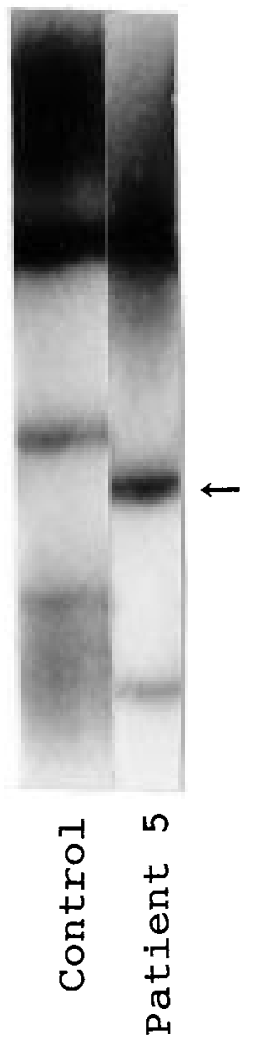

Exon 7

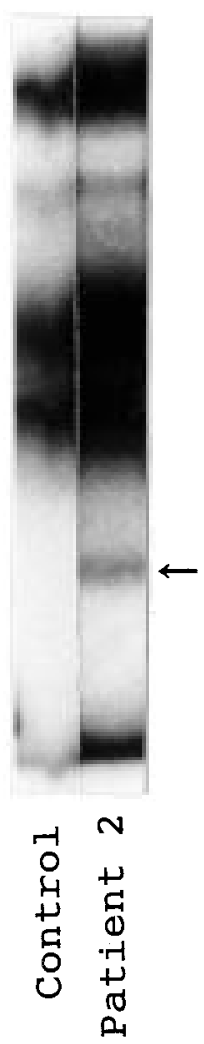

Fig. 1 SSCP analysis of p53 suppressor gene. Arrows show mobility shift SSCP bands.

suppressor gene of a heavy smoker with a biphasic type of tumor. In another patient the change of CGA $\rightarrow$ CGG in codon 213 of the p53 suppressor gene was also found.

Thus, we observed a mutation in the p53 suppressor gene without genetic alteration in the Ha- and Ki-ras oncogenes in one subject. The change in the other subject is considered to have resulted from polymorphism according to the IARC (International Agency for Research on Cancer) information on the polymorphism of $\mathrm{p} 53^{16)}$. These results, together with

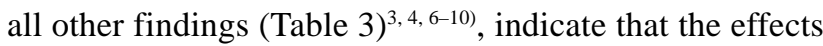
of asbestos on the p53 suppressor gene and Ha- and Ki-ras oncogenes in malignant mesothelioma are negligible.

The mutation in the $\mathrm{p} 53$ suppressor gene was observed only in a heavy smoker in the present study. This suggests a combined effect of asbestos and smoking, although smoking has little or no effect upon the death rate in mesothelioma patients ${ }^{17)}$. Alternatively, other unknown factors might have caused the mutation of the $\mathrm{p} 53$ suppressor gene in this patient. Further studies with a larger number of smokers are necessary to examine whether or not the mutation of the p53 suppressor

gene is caused in malignant mesothelioma due to asbestos and what is the cause of the mutation, if any.

One of the p53 suppressor gene's functions is the prevention of tumor onset, triggering G1 arrest (i.e. termination of cell cycles at the G1 stage before start of the DNA synthesis stage) and apoptosis of DNA-damaged cells. Thus, a mutation in the p53 suppressor gene is considered to lead to tumor onset ${ }^{18)}$.

Analysis of the sequence of the p53 suppressor gene in humans has revealed five conserved regions, regions with a highly similar order of bases in common with various kinds of animals. Four of these regions fall within exons 5 through 8: region ii (Codons 117 to 142), region iii (Codons 171 to 181), region iv (Codons 234 to 258), and region v (Codons 270 to 286$)^{19}$. It is commonly known that mutations of many kinds of natural onset tumors are clustered in these regions ${ }^{20)}$.

Table 4 summarizes reports on p53 suppressor gene mutations in malignant mesothelioma ${ }^{3,4,6)}$. Four of the six mutations reported were located in the conserved regions; the remaining two mutations, both of which were analyzed in primary tumors, were located outside the conserved regions. Thus, further studies are necessary to examine the effects of asbestos on the p53 suppressor gene both within and without the five conserved regions.

The CpG site of the p53 suppressor gene has a high mutability in natural onset tumors. This is because cytosine (C) in this pair is easily methylated and changed to thymine $(\mathrm{T})^{21)}$. On the other hand, four out of the six malignant mesothelioma cases reported had mutations at sites other than $\mathrm{CpG}$ in the p53 suppressor gene (Table 4). The results suggest that the mutation points are different between malignant mesothelioma and natural onset tumors.

The mutation found in the present study was in a biphasic type of tumor. Tumor types have not been reported in other cases except for one case with an epithelial type of tumor ${ }^{6}$, and the relationship between the mutation and the type of tumor cell remains to be studied further.

Manifestation of malignant mesothelioma is characterized by a long latency from the start of asbestos exposure. Clarification of oncogenesis at the gene level would provide a new tool for early detection and treatment of this malignancy.

Finally, it has been reported that polymorphism of the glutathione $S$ transferase $\mathrm{M} 1$ gene and the $\mathrm{N}$ acethyltransferase 2 gene, both of which code detoxic enzymes, plays an important role in the onset of malignant mesothelioma due to asbestos exposure ${ }^{21}$. Further studies into these findings should be also conducted. 
Codon 213 in exon 6

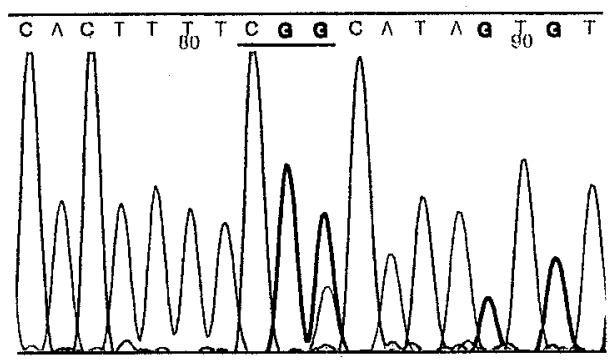

Patient 5

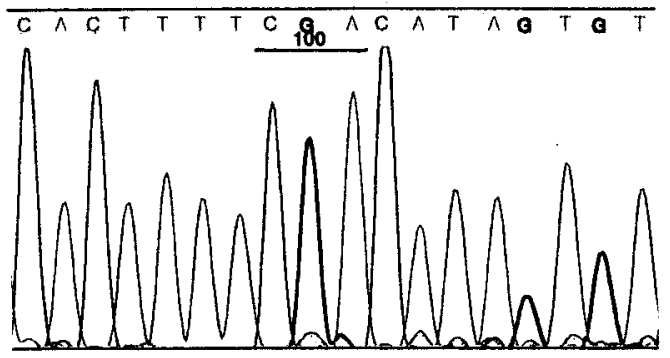

Normal control
Codon 233 in exon 7

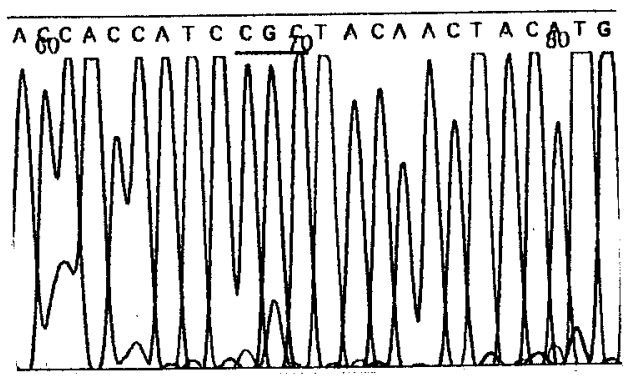

Patient 2

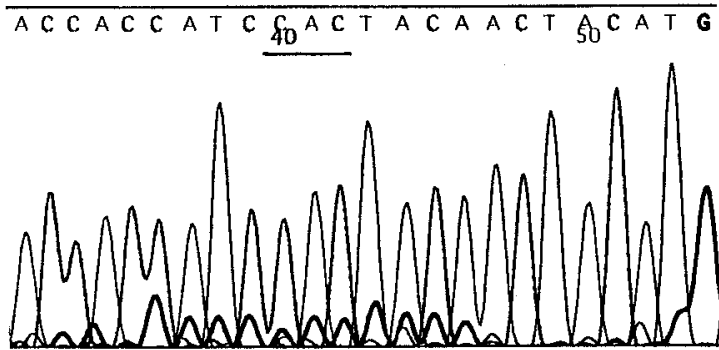

Normal control

Fig. 2 Sequence of $\mathbf{p 5 3}$ suppressor gene.

Codon changes are underlined.

Table 3. Seven Japanese autopsied patients examined in our previous study ${ }^{10)}$

\begin{tabular}{ccclcllr}
\hline No. & Sex & $\begin{array}{c}\text { Death } \\
\text { age }(\mathrm{yrs})\end{array}$ & Occupation & $\begin{array}{c}\text { Asbestos } \\
\text { exposure }(\mathrm{yrs})\end{array}$ & $\begin{array}{c}\text { Type of } \\
\text { Asbestos fiber }\end{array}$ & $\begin{array}{c}\text { Cell type of } \\
\text { mesothelioma }\end{array}$ & $\begin{array}{c}\text { Brinkman's } \\
\text { Index* }\end{array}$ \\
\hline 1 & Male & 61 & Plumber & 20 & Crocidolite & Biphasic & 820 \\
2 & Male & 75 & Carpenter & 18 & Crocidolite & Sarcomatous & 800 \\
3 & Male & 90 & Plumber & 41 & Crocidolite & Epithelial & 550 \\
4 & Male & 67 & Electrician & 35 & Crocidolite & Sarcomatous & 533 \\
5 & Male & 54 & Plumber & 33 & Chrysotile & Epithelial & 0 \\
6 & Male & 52 & Storekeeper & 24 & Chrysotile & Epithelial & 384 \\
7 & Female & 64 & Housewife** & 10 & Chrysotile & Biphasic & 0 \\
\hline
\end{tabular}

* Number of cigarettes per day multiplied by years of smoking. ** Washed clothes of an asbestos worker (her husband) for 10 years.

Table 4. Reports of p53 suppressor gene mutations in malignant mesothelioma

\begin{tabular}{|c|c|c|c|c|c|}
\hline Authors & Material & Codon & Mutation & Conserved region & CpG site \\
\hline Cote et al. $(1991)^{3)}$ & Cell line & 175 & $\mathrm{C} \underline{\mathrm{GC}} \rightarrow \mathrm{C} \underline{\mathrm{AC}}$ & + & + \\
\hline Cote et al. $(1991)^{3)}$ & Cell line & 245 & $\mathrm{GG} C \rightarrow \mathrm{G} \underline{\mathrm{AC}}$ & + & - \\
\hline Metcalf et al. $(1992)^{4)}$ & Cell line & 245 & $\underline{\mathrm{GGC}} \rightarrow \underline{\mathrm{AGC}}$ & + & + \\
\hline Metcalf et al. $(1992)^{4)}$ & Cell line & 278 & $\underline{\mathrm{CCT}} \rightarrow \underline{\mathrm{TCT}}$ & + & - \\
\hline Segers et al. $(1995)^{6}$ & Primary tumor & 266 & $\underline{\mathrm{GGA}} \rightarrow \underline{\mathrm{TGA}}$ & - & - \\
\hline Kitamura et al. (2001) & Primary tumor & 233 & $\mathrm{C} \underline{\mathrm{AC}} \rightarrow \mathrm{CG}$ & - & - \\
\hline
\end{tabular}

3,4,6): References. ${ }^{\text {a): }}$ Present study. +: Satisfied, -: Unsatisfied. 


\section{Acknowledgements}

This paper is based in part on a dissertation submitted for the degree of Doctor of Medical Sciences (DrMSc) at the University of Tokyo. We thank Dr. Shunji Yamamori, Mr. Yoshiyasu Ogawa and other staff of Mitsubishi Kagaku BioClinical-Laboratories, Inc., for their technical assistance. Thanks are also due to Dr. Hajime Sato, Department of Public Health and Occupational Medicine, Graduate School of Medicine, University of Tokyo, for his advice.

\section{References}

1) Wagner JC, Sleggs CA, Marchand P (1960) Diffuse pleural mesothelioma and asbestos exposure in the north western cape province. Brit J industr Med 17, 260-71.

2) Broaddus VC, Yang L, Scavo LM, Ernst JD, Boylan AM (1996) Asbestos induces apotosis of human and rabbit pleural mesothelioma cells via reactive oxygen species. J Clin Invest 98, 2050-9.

3) Cote RJ, Jhanwar SC, Novick S, Pellicer A (1991) Genetic alterations of the p53 gene are a feature of malignant mesotheliomas. Cancer Res 51, 5410-6.

4) Metcalf RA, Welsh JA, Bennett WP, seddon MB, Lehman TA, Pelin K, Linnainmaa K, Tammilehto L, Mattson K, Gerwin BI, et al. (1992) p53 and Kirstenras mutations in human mesothelioma cell lines. Cancer Res 52, 2610-5.

5) Janssen WJ, Lyon J, Steenvorden ACM, Seliger H, Artram CR (1987) Concurrent mutations in two different ras genes in acute myeloid leukemias. Nucleic Acids Res 15, 5669-80.

6) Segers K, Backhovens H, Singh SK, Voecht JD, Ramael M, Broeckhoven CV, Marck EV (1995) Immunoreactivity for $\mathrm{p} 53$ and $\mathrm{mdm} 2$ and the detection of p53 mutations in human malignant mesothelioma. Virchow Arch 427, 431-6.

7) Mayall FG, Jacobson G, Wilkins R (1999) Mutations of p53 gene and SV40 sequences in asbestos associated and non-asbestos-associated mesotheliomas. J Clin Pathol 52, 291-3.

8) Cristaudo A, Vivaldi A, Sensales G, Guglielmi G, Ciancia E, Elisei R, Ottenga F (1995) Molecular biology studies on mesothelioma tumor samples: Preliminary data on H-ras, P21, and SV40. J Environ Ptho Toxico and Oncology 14, 29-34.

9) Mor O, Yaron P, Huszar M, Yellin A, Jakobovitz O, Brok-Simoni F, Rechavi G, Reichert N (1997) Absence of p53 mutations in malignant mesothelioma. Am J Respir Cell Mol Biol 16, 9-13.

10) Kitamura F, Araki $S$, Tanigawa $T$, Miura $H$, Akabane H, Iwasaki R (1998) Assessment of mutation of Haand $\mathrm{Ki}$-ras oncogenes and the p53 suppressor gene in seven malignant mesothelioma patients exposed to asbestos: PCR-SSCP and sequencing analyses of paraffin-embedded primary tumors. Industrial Health 36, 52-6.

11) Goelz SE, Hamilton SR, Vogelstein B (1985) Purification of DNA formaldefyde fixed and paraffin embedded human tissue. Biochemical and biophysical communications 130, 118-26.

12) Saiki PD, Gelfand DH, Stoffel S, Scharf SJ, Higuchi R, Horn GT, Mullis KB, Erich HA (1988) Primerdirected enzymatic amplification of DNA with a thermostable DNA polymerase. Science 239, 487-91.

13) Bos JL (1989) ras oncogenes in human cancer: A review. Cancer Res 49, 4682-9.

14) Hayashi K (1991) PCR-SSCP: A simple and sensitive method for detection of mutations in the genomic DNA. PCR methods and applications 1, 34-8.

15) Hayashi K, Yandell DW (1993) How sensitive is PCRSSCP? Human mutation 2, 338-46.

16) IARC homepage. The IARC database of somatic p53 mutations in human tumors and cell lines: List of common p53 polymorphisms. http://www.iarc.fr/53/ POLY.HTM

17) Hammond EC, Selioff IJ, Seidmann H (1979) Asbestos exposure, cigarette smoking and death rate. Ann NY Acad Sci 330, 473-90.

18) Steele RJ, Thompson AM, Hall PA, Lane DP (1998) The p53 tumor suppressor gene. Brit J Surgery 85, 14607.

19) Soussi T, Caron FC, May P (1990) Structural aspects of the p53 protein in relation to gene evolution. Oncogene 5, 945-52.

20) Vogelstein B, Kinzler KW (1992) p53 function and dysfunction. Cell 70, 523-6.

21) Hollstein M, Sidransky D, Vogelstein B, Harris CC (1991) p53 mutations in human cancers. Science 253, 49-53.

22) Hirvonen A, Pelin K, Tammilehto L, Karjalainen A, Mattson K, Linnainmaa K (1995) Inherited GSTM1 and NAT2 defects as concurrent risk modifiers in asbestos-related human malignant mesothelioma. Cancer Res 55, 2981-3. 


\section{Appendix}

Sequence of the primers ${ }^{10)}$ of PCR used in this study ( $\mathrm{S}=$ sense primer, $\mathrm{A}=$ antisense primer, respectively).

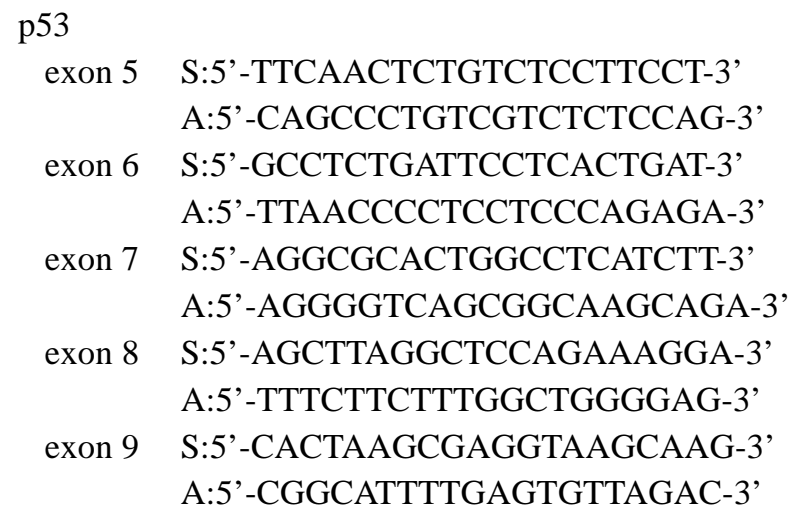

Ha-ras
codon 12,13

S:5'-TGAGGAGCGATGACGGAATA-3' A:5'-TTCGTCCACAAAATGGTTCT-3'

codon 61

S:5'-AGGTGGTCATTGATGGGGAG-3' A:5'-TGGATGTCCTCAAAAGACTT-3'

Ki-ras

codon 12,13

S:5'-GGCCTGCTGAAAATGACTGA-3' A:5'-GTCCTGCACCAGTAATATGC-3'

codon 61

S:5'-GGAGAAACCTGTCTCTTGG-3'

A:5'-CACAAAGAAAGCCCTCCCCA-3' 